\title{
Impact pathways of a participatory local governance initiative in Uganda - A qualitative exploration
}

\author{
Bjorn Van Campenhout ${ }^{*}$, Emmanuel Bizimungu ${ }^{\S}$, Jennifer Smart ${ }^{\ddagger}$ and Nassul Kabunga ${ }^{\S}$
}

\begin{abstract}
The baraza project, initiated in 2009, is a government-led initiative in Uganda that aims to increase the quality of public service delivery through the provision of information and involvement of beneficiaries in project monitoring by means of providing citizens with an advocacy forum. This study provides a qualitative assessment of the selfidentified pathways through which barazas are thought to influence public service delivery, as expressed by participant stakeholders. It also explores motivating factors behind behavioral changes of stakeholders, hindrances to achieving positive outcomes, and opportunities for the implementation of future barazas.
\end{abstract}

Keywords: Governance and public policy; Civil society - participation; Social sector - Education, Health, Water and sanitation

\section{Introduction}

Uganda's economic liberalization efforts in the mid-1980s and subsequent decentralization drive in the early 90 s profoundly altered public service provision. However, public service delivery has continued to suffer from ineffective monitoring and weak accountability mechanisms, especially with respect to beneficiaries holding the service providers accountable (Francis and James 2003). For example, Reinikka and Svenssons (2004) document massive elite capture of funds in the education sector. Follow up studies showed that the provision of information and involvement of beneficiaries through village meetings can significantly improve both quantity and quality of public service delivery (Reinikka and Svensson 2011, Bjorkman and Svensson, 2009).

In response to the lack of monitoring and poor accountability processes, the government of Uganda initiated the baraza project in $2009^{1}$. Barazas are citizen advocacy forums that aim to "enhance public involvement in holding the government accountable for service delivery in relation to the resources spent" (OPM 2013). They are initiated by the

\footnotetext{
* Corresponding author, International Food Policy Research Institute and LICOS Centre for Institutions and Economic Performance - KULeuven, Waaistraat 6 - bus 3511 - B-3000 Leuven - Belgium; bjorn.vancampenhout@gmail.com

$\S \quad$ International Food Policy Research Institute - Kampala office - 15 East Naguru Road - Kampala Uganda 
Office of the Prime Minister (OPM), and organized at the sub-county or district level. Barazas bring together government officials, policy makers, public service providers, and users of public services. Key sectors for discourse include agriculture, education, water and sanitation, health, and infrastructure.

Currently, a large-scale impact evaluation of the baraza initiative, funded by the International Initiative for Impact Evaluation (3ie) and implemented by a team of researchers from the International Food Policy Research Institute (IFPRI), is ongoing ${ }^{2}$. Through a cluster randomized control trial, it will quantify the impacts of the baraza initiative on quantity and quality of public service delivery in each of the sectors mentioned above. The quantitative research design will also allow the comparison of the relative effectiveness of the two main components of a baraza: (1) information provision, whereby officials report on planned activities and achievements, and (2) deliberation, whereby citizens are encouraged to engage with and challenge civil servants. Furthermore, the quantitative analysis will allow comparison of district level barazas to barazas that are held at the lower sub-county level. While such a quantitative approach provides the best way to empirically establish causal claims, an important criticism is that these methods merely provide a black box view of causality and often fail to identify the mechanisms that link the intervention to the outcome. However, especially in the context of economic development, one does not only want to know if something works or does not work, but also why (Deaton, 2009).

In this paper, we take a qualitative research approach to explore the potential causal pathways that underlie outcomes that may emanate from baraza interventions and the behavioral change of actors, as well as examining hindrances to achieving positive outcomes and opportunities for the implementation of future barazas. Based on a series of semistructured interviews with (a) politicians as the principals initiating and monitoring the services; (b) civil servants as the agents delivering the services; and (c) citizens as the clients consuming the services, we explore likely impacts of the baraza interventions. In doing so, we engage these stakeholders to articulate their preconceptions of how the baraza will or will not achieve impact, also known as the "theory of change". As such, the qualitative analysis can help to identify potential impact pathways of the barazas, providing essential feedback as the basis for empirical cross-validation and potential revision of the theory of change underpinning the ongoing quantitative study.

We find that stakeholders think barazas are useful at improving public service delivery across all sectors, especially if the barazas took place at the sub-county level. Stakeholders had no difficulty providing examples of changes they felt were the direct result of the baraza being held: projects that were previously dragging were finished or taken up afresh; sub-standard work was redone; and in some instances, priorities were changed to better align with citizens' needs. A substantial part of these outcomes seemed to derive from the baraza's potential to simply fix information asymmetries. The focus group discussion suggest civil servants responded to the consequences of the increased likelihood of substandard work being exposed, and politicians responded to electoral considerations. There are also indications that barazas increased community involvement, as well as top-down monitoring. 
The structure of the remainder of this paper is as follows: The following section lays out the research questions and situates the study within the large body of literature related to citizen participation and governance. The next section provides a detailed description of a baraza event, offers a summary of the primary stakeholders involved in it, and presents the methodology used to interview them and gives background information on the study area. Section four presents the results: this section reports impact of baraza intervention as perceived by the different stakeholders organized by sector, gives possible reasons for this change, and motivating factors for behavioral change. We also reflect on factors that may reduce the effectiveness of the barazas, and suggest some improvements. A last section concludes.

\section{Research questions and situation within the wider literature}

In both the quantitative impact evaluation and this exploratory qualitative study, the overarching research question is whether community monitoring initiatives, such as the baraza programme, can improve the quantity and quality of public services in different sectors. However, as mentioned above, a quantitative impact evaluation is less suited to find out why such initiatives work.

Finding out the mechanisms through which an intervention is connected to its outcomes is important to understand why the intervention may work more in some cases and less in other cases, leading to so-called treatment heterogeneity. It may also suggest ways in which the intervention can be made more effective, and what preconditions are needed to maximize impact.

Therefore, this research is an important complement to quantitative work and focusses on exploring the reasons behind (observed or perceived) impacts of the baraza intervention. In particular, we investigate if self-assessed changes can be linked to what has transpired in a particular baraza event by the different actors, and inquire about the reasons for, and motivations behind these changes. In addition, we ask if there are certain factors specific to the particular baraza that may have prevented it from being (even more) effective and what can be done to make it even more effective.

At the same time, care should be taken in generalizing findings of a qualitative study such as this one. Local realities affect outcomes, and these may differ between locations. A nationally representative quantitative study that estimates average differences between areas that received a baraza and those that did not receive a baraza would be more appropriate to such extrapolations of the findings.

This research fits into the large body of literature on decentralization, community governance, accountability and public service delivery. Most of the research in this area are rigorous quantitative studies using field experiments, and as such, our qualitative exploration is an important contribution in understanding the mechanisms behind some of these findings. As it is beyond the scope of this article to give a full overview of this literature, we restrict ourselves here to studies that we feel are closest to our study. 
Participation of direct beneficiaries has been studied most extensively in public health. Changes in birth outcomes and neo-natal mortality have been attributed to community participation, often through increased involvement of women groups (eg. Manandhar et al. 2014; Azad et al 2010). But also in the education sector, participation has been found to improve a range of outcomes. For instance, Pandey et al (2009) report increased teacher effort and modest improvements in learning outcomes as a result of a community-based information campaign in three Indian states. Jimenez and Sawada (1999) find that in El Salvador, f enhanced community and parental involvement in schools has improved students' language skills and diminished student absences, which may have long-term effects on achievement. Probably closest in spirit to a baraza meeting, Olken (2007) compares representative-based meetings with direct election-based plebiscites. Plebiscites resulted in dramatically higher satisfaction among villagers, increased knowledge about the project, greater perceived benefits, and higher reported willingness to contribute.

Due to the far reaching decentralization efforts, Uganda has been a popular case among governance research. The most important studies were already mentioned in the introduction. Reinikka and Svenssons (2004) document massive elite capture of funds in the education sector. Their follow up study showed that a newspaper campaign aimed at reducing capture of public funds by providing schools (parents) with information to monitor local officials' handling was highly successful and reduced capture, in turn increasing enrollment and student learning (Reinikka and Svensson 2011). Bjorkman and Svensson (2009) reports on a randomized field experiment on community-based monitoring of public primary health care providers in Uganda. Interventions very similar to barazas resulted in treatment communities being more involved in monitoring the provider, and the health workers appear to exert higher effort to serve the community

Related to the fact that information dissemination is a key component of a baraza, Grossman and Michelitch (2018) disseminate information about job performance for randomly selected Ugandan politicians. They find that job performance increases among a range of criteria, but only in constituencies where there the opposition is active. They do not find an impact on public service provision, suggesting that the information about the performance of public servants in addition to information on politicians only may be necessary. However, a similar study by Humphreys and Weinstein (2012) did not find any effect, maybe because they did not account for the level of political competition.

Using observational data, Deininger and Mpuga (2005) find that if a household lacks knowledge on procedures to report corruption, this increases the households' risk of being subject to bribery and significantly reduces the quality of public service the household receives. An important study that are more qualitative in nature paint a less optimistic picture. Using the health sector in Uganda as a case study, Frederick Golooba-Mutebi (2005) argues that to succeed in the long term, devolution and participation must take place in the context of a strong state, able to ensure consistent regulation, and a well-informed public backed up by a participatory political culture.

\section{A qualitative assessment of the baraza and its players}




\section{The baraza event}

The baraza project, initiated in 2009, is a government-led initiative in Uganda that aims to increase the quality of public service delivery through the provision of information and involvement of beneficiaries in project monitoring by means of providing citizens with an advocacy forum. Operationally, a single baraza event (or simply called, baraza) is expected to be conducted twice a year at the level of the subcounty to track the planned activities and achieved outcomes. In the current form, the Office of the Prime Minister (OPM) coordinates the baraza activities in every district by mobilizing district and subcounty officials including the Chief Administrative Officer (CAO), the Resident District Commissioner (RDC), the District Local Council Chairperson (LCV), sector heads, and subcounty administrative officers (chiefs), among others. Village mobilizers are used to disseminate information and explain the baraza concept to the populace. These community mobilization efforts are further reinforced by adverts in the local media in the form of radio announcements; printed banners, posters and fliers; and mobile public address systems, a few days before the baraza event.

Until now, every baraza in Uganda has been initiated, coordinated and logistically supported by the OPM, independent of the local governments. If a baraza is to be held in a given location, the OPM, in consultation with the district leaders (RDC, CAO and the LCV) and other stakeholders, agree on the date and a neutral venue in which to hold the baraza event. Again, in consultation with the district leaders, a viable moderator and an interpreter into the local language where applicable are identified to guide the baraza forum, in which sector heads make presentations and respond to queries raised by the community. Baraza moderators are expected to be objective, of high integrity and have the trust of the community. Moreover, they should be knowledgeable about government programs in a given locality.

On the chosen date and venue, a baraza meeting is chaired by the Office of the RDC in each district. In front of the audience, including local citizens and invited opinion leaders and elders, the RDC seeks accountability and feedback from each head of major sectors, which are: health, education, physical infrastructure (mainly water facilities and roads), and agriculture (particularly national agricultural advisory services - NAADS) by asking them to present on:

a. What services were planned to be delivered in the subcounty?

b. What was actually delivered and in what quantity and quality?

c. What issues and challenges have emerged and what is the way forward?

The RDC then seeks reactions and feedback from citizens on whether what has been presented is what was planned for and actually implemented in different locations. Sector heads are then given another opportunity to clarify on or react to any issues raised by the citizens. At the end of the process, the RDC makes a report to the OPM, indicating issues that arose in the baraza meeting. This report particularly points out policy and program implementation weaknesses and challenges, which further feeds into the general government performance management system. A typical baraza starts at around 11 in the morning and lasts up to 5 in the afternoon. It is attended by about 100-200 citizens. 


\section{Key stakeholders}

A baraza aims to provide a platform where three types of stakeholders interact: politicians, civil servants and citizens. Elected politicians initiate and formulate development plans, and oversee and monitor the implementation of policies and programs. They are mandated by the citizens, and as such should be sensitive to their priorities and uphold their interests. Second, citizens are the main beneficiaries of the public services. They contribute through user fees, taxes, or in some cases directly through labor and are required to utilize the services according to regulations and safeguard public infrastructure. Third, there is the technical staff, who are contracted by government and are responsible for service provision and implementation of government programs and projects.

Under the local government system, there are five administrative levels, organized as local councils (LCs), within the districts of Uganda. The lowest administrative level is the LC I, responsible for an individual neighborhood or small village. LC II through LC IV cover a range of sub-district local government while the LC V has responsibility over the district. A council is the highest political authority within the area of jurisdiction of local government; and has the legislative and executive powers which are exercised in accordance with Uganda's constitution. In regard to public service delivery in rural Uganda, LC III and LC V at sub-county and district level, respectively are the most important political and administrative units.

On a given baraza event, the three stakeholder categories are each represented by both district level and sub-county level equivalents. The political wing is represented by the District LC V Chairperson and the Sub-county LC III Chairperson. These actors preside over committees that initiate projects, approve budgets and monitor government programs and service delivery. The service providers are also assumed to be represented at both LC III and LC V levels. Civil service at the district level is headed by the Chief Administrative Officer (CAO). Each sector also has a sector heads (e.g. agriculture, education, health, and roads) that is also expected to attend the baraza event. The sub-county equivalent of the CAO is the subcounty chief. There may also be civil servants that are responsible for different sectors at the sub-county level. While most of the information will be provided by the district level politicians and civil servants, the district level officials may provide clarification if needed.

To date, the majority of barazas were organized at the sub-county, but some have also take place at district level. It is important to note that even when the baraza is organized at the sub-county level, the main representatives for the government that are invited to the baraza are from the district level. The CAO and each sector head present plans and accomplishments for the sub-county.

\section{Methodology}

We use semi-structured interviews with focus groups consisting of different stakeholders, at both district and sub-county level, to elicit key political and socioeconomic differences that can be implicitly linked to the baraza intervention. We interviewed (1) the political leaders in selected districts and sub-counties responsible for planning, approval and 
monitoring of the various government programs and projects, (2) the technical staff responsible for service provision, (3) residents/citizens as the main beneficiaries of public services, (4) community baraza facilitators, and (5) other key informants knowledgeable about the baraza and public service provision.

Politicians such as LC chairs were interviewed in one-on-one interviews, to enable them to speak more freely. CAOs were also interviewed individually. Sector heads where interviewed in small groups of 2 or 3 people. Citizens were interviewed in groups of between 5 and 10 people. For citizens, we made sure to have a representative group of society, making sure to include youth, women, farmers, businessmen, CSO members, etc. We conducted interviews at both the district level and sub county level. In total we conducted about 20 interviews, of which 2 were focus groups with citizens and 3 were semi-structured interviews with small groups of service providers and the rest were semi-structured interviews with politicians, higher level civil servants and experts.

Both semi-structured interviews and focus groups discussions were structured around three questions. The interviews began with a general question, asking if a particular stakeholder thought public service delivery in any sector had changed after the baraza. We then often probed if information about this aspect of public service delivery was given during the baraza or if the topic was discussed during the baraza.

Second, we asked each of the three main actors (politicians, civil servants and citizens) if the performance, behavior or perceptions of the other stakeholders had changed after the baraza. For instance, we asked citizens if they felt civil servants such as doctors and nurses addressed concerns that were brought up during the baraza. We asked if citizens thought politicians changed their behaviour in some way as a result of the baraza. In a similar way, we also asked politician if civil servants changed their behavior after a baraza. The same politicians were also asked if citizens have changed their behaviour or expectations as a result of the baraza. Finally, civil servants were asked if politicians now act differently from how they acted before the baraza, and if citizens changed behavior following the event.

Third, we inquired about likely motivations behind any of the observed changes in performance, behaviour or perceptions of stakeholders. For instance, we asked citizens what they thought led civil servants to change behavior or about the likely consequences if they had not altered their behavior. Again, these kinds of questions were asked to each stakeholder group, concerning their impressions of the other stakeholder groups.

\section{Context}

Interviews were conducted in Bagezza Sub-county of Mubende District where a subcounty baraza was held on 16th September 20163. About 210 people attended the baraza in Bagezza Sub-county. Bagezza consists of 8 parishes. The five sectors of agricultural production, education, health, water and sanitation as well as rural road infrastructure were discussed and issues and concerns raised. The event was coordinated and attended by the RDC4. The baraza was also attended by the Minister of General Duties in the OPM, the LC 
$\mathrm{V}$, the CAO and sector heads. Participants were reportedly very assertive, many pointing out empty promises made by the government.

We can use the baseline data that was collected as part of the quantitative impact assessment to get an idea of how the sub-county is doing compared to the overall average in Uganda (Kabunga et al 2016). For instance, with respect to public service delivery in the agricultural sector, we find that about 11 percent of households received a visit at the home from an extension officer in the previous year. In Bagezza sub-county, this proportion is slightly higher. Only about 12 percent of households report that they received a visit of a member of the Village Health Team, suggesting poor performance of the public health system within the sub-county. For the country as a whole, more than half of the households report they have received a visit in the last year. Looking at the main source of water, we find a very high reliance on rainwater in Baggeza. While on average about 22 percent of households depend on rain as their main supply of water, this percentage is as high as 70 in the subcounty. When we asked villagers to rank sectors, we find that water is the main problem within the district, with 43 percent of households mentioning this is the most important sector that needs improvements. This share is 30 percent for Uganda as a whole.

The second location of interviews was in Masindi, where a district level baraza was held on 14th October 20165. This baraza was also fairly attended with representatives from the OPM, the district political and technical teams making presentations and receiving feedback from the citizens as appropriate. Discussions quickly revealed challenges in the district due to poor working relationship between the political (LC V) and technical (CAO) leaders of the district.

We can again use data from the baseline to get a sense of the relative state of public service delivery within the district. For agriculture, only about 4.8 percent of households were visited by an extension worker in the previous year, while this was 11 percent nationwide. For the health sector, we find that almost 30 percent of households within the district were visited by someone from the Village Health Team in the past 12 months. While this is higher than the proportion reported in Bagezza sub-county, this is still substantially below the national average. In Masindi, most households seem to obtain water from a protected source (53 percent, while the national average 46 percent). In the district, 31 percent of households mentioned health is the most important sector, closely followed by water. These proportions are in line with the national averages.

\section{Results}

\section{Self-assessed impact}

According to the respondents in this study, the barazas were generally useful at improving public service delivery across all sectors, especially in Bagezza where the barazas took place at the sub-county level. Stakeholders had no difficulty providing examples of changes they felt were a direct result of the baraza that was held: projects that were previously dragging were finished or taken up afresh; sub-standard work was redone; stolen 
goods were recovered; absenteeism was reduced; priorities were changed to better align with citizens' needs. We provide a selection of examples below.

Examples of how barazas can speed up projects were provided in Bagezza Subcounty. During the baraza, residents complained that the government promised a "seed" secondary school in Mugungulu Parish, but that no follow-up action had ensued ${ }^{6}$. During the baraza, officials from the education department explained that the district accounts had recently received substantial funds from the central government for the construction of this school. After the baraza, land surveying took place and it was reported that the government had hired 21 new teachers in January 2017, giving the impression that plans for the school's construction and operationalization were becoming more concrete. According to stakeholders interviewed, the barazas were important in making this information available to all parties involved.

We also found many examples of how a baraza can uncover sub-standard work and lead to corrective action: At the Masindi District baraza, it was reported that work on the construction of a soak pit was not complete, even though a proof of completion had been issued by the contractor. As a result of the baraza, the concern was followed up and the contractor was forced to finish the job. In Masinidi, market vendors forced district authorities to replace poor quality anti-burglary windows which had been installed in a new market building.

Citizens that attended the Baggeza Sub-county baraza raised complaints of medical staff absenteeism in health centers and poor conduct by health workers. In response, the health sector head explained that many of the medical staff were on study leave. This information prompted the RDC to request that the CAO should compile a list medical staff with detailed information about the study leave and put in place disciplinary measures to reduce absenteeism that is not related to study leave. After the discussion at the baraza, respondents reported that health staff started reporting at $8 \mathrm{am}$, when formerly, they came in at 11 am or noon.

Also at the Masindi District baraza, a mismatch was uncovered between the number of motorcycles destined for distribution to rural health centers as reported by the District Health Officer and the actual number of the motorcycles distributed. After this was raised at the baraza, all the motorcycles were recovered and distributed to the intended centers. A tractor and an insemination machine that had been lost was recovered.

The most compelling example of how a baraza can align priorities to the needs of citizens was given in Masindi. Here, financial resources had been allocated to widen a particular stretch of road where a few serious accidents had taken place in the recent past. However, during the baraza, the situation in Kiizi swamp was highlighted: A bridge had been washed away there, and children on one end of the bridge could no longer cross get to the school on the other side. After the baraza, priorities were changed and the Kiizi bridge was considered an emergency. Since the baraza, the bridge has been repaired and even some additional work on the road has been completed. 


\section{Impact pathways}

A substantial part of these outcomes seemed to derive from the baraza's potential to simply reduce information inefficiencies. For example, the Bagezza Sub-county LC III Chairperson noted that provision of more information during a baraza is important because citizens get to understand what 'belongs' to them. The example of the school was used: Both technical and political staff at the sub-county level heard of the plans to open a new school in the sub-county, but it was only after questioning the CAO during the baraza that they learned that the funds were there and a school board meeting had already taken place. More in general, the LC III Chairperson emphasized the fact that barazas gave him information on what communities prioritize. One example of this was the creation of a WhatsApp group as an information sharing platform to report about service delivery issues in the district.

A second major perceived impact pathway was increased top-down monitoring. According to the Sub-county Chief of Baggeza Sub-county, barazas are capable of exposing shoddy work. Therefore, the baraza makes service providers more conscious of the quality of their work. Health assistants now go to communities to inspect households. Councilors now make sure they know what is in the sub-county budget. For new projects initiated at the subcounty, the Sub-county Chief now receives full details about them and she is instructed to supervise the work of these projects. All this did not happen in such a systematic and organized manner before the baraza.

One particularly interesting observation from the Masindi Town Clerk (equivalent of the Sub-county Chief for urban sub-counties) was that councilors "learned to monitor" projects as a result of the baraza. According to the Town Clerk, there have been significant changes in the way councilors interpret reports and in the type of questions that councilors ask technocrats. According to the Town Clerk, politicians in Uganda are often poorly educated. After a baraza, he noticed that politicians started to imitate more vocal and educated citizens such as Civil Society Organization (CSO) members or local businessmen who often speak out during barazas.

Another perceived impact pathway was related to increased community involvement in monitoring government projects. For example, in Masindi, a local councilor reported that local citizens are now better informed as to when a project starts, what it entails and when it is expected to be finished. The local citizens are also provided with the Bill of Quantities (BOQ) to make sure that what they expect corresponds to what was planned (e.g. only a murram road was planned when citizens may expect a tarmac highway). Villages are even encouraged to set up their own monitoring teams to make sure no fuel and other supplies are stolen.

\section{Motivation}

Service providers acknowledged that citizens are now more compelled to report service delivery issues than before and that their complaints are holding service providers to account. The increased flow of information about what is expected and what has actually happened with respect to public service delivery leads to a change in service providers' norms 
and practices due to a fear that they will be reported to their bosses such as the CAO and LC $\mathrm{V}$ chairman and that this may result in indictment. For example, in Masindi District, an engineer and his whole staff were arrested and a Sub-county Chief in one sub-county was indicted as a result of endorsing payments for shoddy work. The contractor was paid a sum of 11 million Ugandan Shillings (roughly 3,000 USD) for work that was only valued at Uganda Shillings 2.5 million. This incident was confirmed by citizens that attended the district level baraza in Masindi.

Citizens mentioned that service providers fear to be arrested. They fear that citizens will report shoddy work or irregularities. A Masindi District council member noted that some service providers have been summoned to the parliamentary public accounts committee.

Politicians stated that they are beginning to fear that if they do not do their job to utmost satisfaction, they will not be voted into office when their mandate expires in 2021. This has reduced corruption. For example, civil servants and politicians who would connive to award themselves contracts have stopped. Politicians have pulled out of tender bids once they realize that a time will come to account to the citizens. Before the baraza, civil servants would often be held at ransom by politicians; civil servants would make a budget but the politician, who often are signatories, would not approve the budget unless their companies are awarded lucrative deals.

\section{Limits to baraza}

Focus group discussion suggest barazas are a good governance tool to curb corruption tendencies, improve accountability and public service delivery. However, a baraza can only be effective if there is follow up by all stakeholders involved. In particular, it is important that a subsequent baraza is organized in the same area in a relatively short period such that residents can be updated on the steps taken to resolve the issues raised at the previous baraza. In principle, OPM is supposed to initiate barazas every six months but this has not happened as designed. Failure to follow up on issues raised during the baraza, both in terms of action and information, may be a real threat to barazas as a governance tool. The optimism among the stakeholders, the citizens in particular, may quickly turn into disappointment if none of the issues raised during the baraza is addressed, leaving communities worse off than before the baraza. This is also reflected in a recent study by Buntaine et al (forthcoming). They warn that there can be unexpected consequences of information sharing among citizens, such that citizens who were previously unaware or unaffected by a problem in a neighboring village may become aware of an issue being discussed in a way that leads to an increased sense of disempowerment or exclusion. This recent study showed that information sharing actually led to new resentments rather than helping to drive participatory community-led development.

Another clear hindrance to achieving improved outcomes from the introduction of a baraza in a community, is the often poor relationship between politicians and technical personnel. Particularly in Masindi, we found that the relationship between the CAO and the LC V Chairperson was quite reprobate. We received signals that the situation got even worse after the baraza (culminating in the Chairperson confiscating the CAOs vehicle because the 
latter used the vehicle after business hours). It may not be conducive for service provision if a baraza exposes issues beyond accountability mishaps to the wider public.

Some of the issues that are mentioned during the barazas simply fall under the responsibility of higher levels of government or other institutions that are beyond the operational jurisdiction of the stakeholders of a baraza. One example that was mentioned was related to the functioning of the public extension system known as Operation Wealth Creation (OWC). After the baraza, citizens understood that OWC was out of the control of district government, but obviously, this did not solve the problem.

The limits of what a baraza at a certain level of government can achieve was also mentioned by the Masindi District CAO. The CAO noted that he has personally forwarded some of the policy level issues to the center for consideration. He also noted that lower local governments now know that they are there to serve people. He however noted that not all issues should be handled by his office since his office may not have the capacity to reach everywhere and on time. He gave the example that health related issues or complaints should be handled by Health Unit Management Committees (HUMCs) rather than forwarding them to the CAO.

\section{Opportunities for Future Barazas}

Future barazas can be improved by making sure barazas are announced early enough for information to be passed from posters, for example, to as many people as possible, especially given that word of mouth advertising is a primary vehicle for publicizing information, in part due to the high rates of illiteracy in the area. Furthermore, when barazas are publicized earlier, it allows citizens the opportunity to look for transport to the baraza venue, especially for those traveling from far away parishes.

Many participants requested greater engagement in simultaneous citizen education. For example, while the Mubende District CAO was supportive of the idea behind the baraza, he stressed that the approach should be changed to fully encompass an integrated civic education component. He voiced his frustration that citizens often expect too much from service providers and complain about things that are citizen's own responsibility. As a service provider, there is only so much one can (and should) do: Service providers construct boreholes but citizens should still boil water before drinking (instead of complaining that the water from the bore hole makes them sick); Service providers can provide farmers with seeds but it is up to the farmer to apply recommended practices to achieve a good harvest.

Citizens that received district level barazas mentioned that barazas should not stop here, but should also drill down to lower (sub-county) levels. The Masindi District CAO contends that barazas should be organized at the sub-county level as well as the district level, to get a more complete view of the diversity of government programs and projects. Moreover, it becomes complicated for citizens to trek long distances from their communities to attend barazas at the district headquarters.

\section{Conclusions}


This paper explores the self-assessed causal pathways that underlie changes in outcomes that may emanate from baraza interventions in Uganda and the behavioral change of actors. From discussions held with different stakeholders, we examine hindrances to achieving positive outcomes of the baraza and indicate opportunities for the improvement of future barazas. This analysis will benefit the proper alignment of causal pathways in the forthcoming quantitative impact evaluation. Lessons learned from these assessments will improve the OPM in planning and implementation of future barazas with the ultimate goal of enhancing public service delivery.

We focus on two barazas, one held at the district level and the other at the lower subcounty level. For each baraza, we perform a series of focus group discussions with the 3 main stakeholders (politicians, civil servants and citizens), as well as some additional semistructured interviews with experts. We inquire about changes that happened since the baraza was held and are likely to have happened because the issue was raised during the baraza. We also ask respondents to reflect on how this change came about and what motivated agents involved to affect the changes. We also point out some of the factors that may reduce the effectiveness of the barazas and provide some recommendations for improvements.

In general, stakeholders were very positive about barazas. We were able to collect a long list of improvements that were thought to emanate from the baraza. Barazas seem to be especially important to reduce information asymmetries, as government officials learn about the priorities of the citizens and citizens' often unrealistic expectations are matched up against reality. In addition, the bottom-up approach of the baraza leads to an increase in top-down monitoring, as officials learn from vocal citizens how to scrutinize public services delivered.

Failure to follow up on the issues raised during baraza is a real thread to the baraza model. As a baraza raises awareness about issues and increases expectations, it may backfire if no action ensues. People may become disillusioned and completely lose faith in government and service providers

Instead of just holding government accountable, barazas can also become a platform to collectively reflect on how inputs can be most effectively translated into outcomes, and what the role of each stakeholder is. Attention for civic education, where citizens are sensitized about proper use of services and their responsibility in maintaining public infrastructure, are also important to lead to improved outcomes in terms of general wellbeing.

\footnotetext{
1 Baraza is a generic term for "meeting" in Uganda. Barazas are organized by different actors in Uganda, especially Non-Governmental Organizations (NGOs) and Civil Society Organizations (CSOs). The baraza's we are studying here are the "official" ones that are initiated by the Office of the Prime Minister.
}

2 See http://www.3ieimpact.org/en/evidence/impact-evaluations/details/2905/ for more information.

3 Interviews were conducted in July 2017. As such, about 10 months have passed since the sub county baraza was held. 
4 The Resident District Commissioner (RDC), a government-appointed positions at the district level, is assigned the purpose of representing the national government's interests.

5 Interviews were conducted in July 2017. As such, about 9 months have passed since the district baraza was held.

6 Seed schools were established by the Government in sub-counties for the implementation of the Universal Secondary Education programme. 


\section{References}

Azad, Kishwar, Sarah Barnett, Biplob Banerjee, Sanjit Shaha, Kasmin Khan, Arati Roselyn Rego, Shampa Barua et al. "Effect of scaling up women's groups on birth outcomes in three rural districts in Bangladesh: a cluster-randomised controlled trial." The Lancet 375, no. 9721 (2010): 1193-1202. doi: 10.1016/S0140-6736(10)60142-0

Bjorkman, Martina, and Jakob Svensson. "Power to the people: evidence from a randomized field experiment on community-based monitoring in Uganda." Quarterly Journal of Economics 124, no. 2 (2009): 735-769. doi: 10.1162/qjec.2009.124.2.735

Buntaine, Mark T., Brigham Daniels, and Colleen Devlin. "Can information outreach increase participation in community-driven development? A field experiment near Bwindi National Park, Uganda." World Development (2017). doi: 10.1016/j.worlddev.2017.10.029

Deaton, Angus S. Instruments of development: Randomization in the tropics, and the search for the elusive keys to economic development. No. w14690. National Bureau of Economic Research, 2009. doi: 10.3386/w14690

Deininger, Klaus, and Paul Mpuga. "Does greater accountability improve the quality of public service delivery? Evidence from Uganda." World development 33, no. 1 (2005): 171191. doi : 10.1016/j.worlddev.2004.09.002

Francis, Paul, and Robert James. "Balancing rural poverty reduction and citizen participation: The contradictions of Uganda's decentralization program." World Development 31, no. 2 (2003): 325-337. doi: 10.1016/S0305-750X(02)00190-0

Grossman, Guy, and Kristin Michelitch. "Information Dissemination, Competitive Pressure, and Politician Performance between Elections: A Field Experiment in Uganda." American Political Science Review (2018): 1-22. doi: 10.1017/S0003055417000648

Humphreys, Macartan, and Jeremy Weinstein. "Policing politicians: citizen empowerment and political accountability in Uganda preliminary analysis." Columbia Universities. Unpublished manuscript (2012). Online: http://cu-csds.org/wpcontent/uploads/2009/10/ABCDE-paper.pdf

Jimenez, Emmanuel, and Yasuyuki Sawada. "Do community-managed schools work? An evaluation of El Salvador's EDUCO program." The World Bank Economic review 13, no. 3 (1999): 415-441. doi: 10.1093/wber/13.3.415

Kabunga, Nassul, Tewodaj Mogues, Emmaneul Bizimungu, Alvina Erman, and Bjorn Van Campenhout (2016). The State of Public Service Delivery in Uganda. Report of a Baseline Survey. International Food Policy Research Institute (IFPRI), online: http://www.ifpri.org/publication/state-public-service-delivery-uganda-report-baseline-survey

Manandhar, Dharma S., David Osrin, Bhim Prasad Shrestha, Natasha Mesko, Joanna Morrison, Kirti Man Tumbahangphe, Suresh Tamang et al. "Effect of a participatory 
intervention with women's groups on birth outcomes in Nepal: cluster-randomised controlled trial." The Lancet 364, no. 9438 (2004): 970-979. doi: 10.1016/S0140-6736(04)17021-9

Office of the Prime Minister (2013). Implementation of the Baraza initiative: Progress report. Kampala: Uganda, Government of Uganda.

Olken, Benjamin A. "Monitoring corruption: evidence from a field experiment in Indonesia." Journal of political Economy 115, no. 2 (2007): 200-249. doi: 10.1086/517935

Pandey, Priyanka, Sangeeta Goyal, and Venkatesh Sundararaman. "Community participation in public schools: impact of information campaigns in three Indian states." Education economics 17, no. 3 (2009): 355-375. doi: 10.1080/09645290903157484

Reinikka, Ritva, and Jakob Svensson. "Local capture: evidence from a central government transfer program in Uganda." The Quarterly Journal of Economics 119, no. 2 (2004): 679705. doi: 10.1162/0033553041382120

Reinikka, Ritva, and Jakob Svensson. "The power of information in public services: Evidence from education in Uganda." Journal of Public Economics 95, no. 7-8 (2011): 956-966. doi: 10.1016/j.jpubeco.2011.02.006 